\title{
Histoplasmose disseminada e SIDA. Importância do meio de cultivo para o espécime clínico-broncoscópico
}

\author{
Disseminated histoplasmosis and AIDS. The role of culture \\ medium for the bronchoscopic clinical specimens
}

\author{
Gisela Unis ${ }^{1}$, Vanusa Barroso da Silva ${ }^{1}$ e Luiz Carlos Severo ${ }^{1}$
}

\begin{abstract}
RESUM0
A fibrobroncoscopia é um procedimento útil no diagnóstico da histoplasmose, quando o material clínico é processado adequadamente. São apresentados dez casos de histoplasmose disseminada em pacientes com SIDA, com avaliação micológica em cultivo, nos meios Mycosel ${ }^{\circledR}$ e ágar-Sabouraud cloranfenicol de espécimes clínicos colhidos por fibrobroncoscopia. A positividade do cultivo em $\mathrm{Mycosel}^{\circledR}$ foi de $60 \%$, enquanto no ágar-Sabouraud cloranfenicol foi de $20 \%$, evidenciando a importância do meio seletivo no isolamento do Histoplasma capsulatum var capsulatum de espécimes clínicos potencialmente contaminados, bem como a importância das informações clínicas para o laboratório, sendo esta a chave para o diagnóstico correto.
\end{abstract}

Palavras-chaves: Histoplasmose. SIDA. Histoplasma capsulatum var. capsulatum. Isolamento em cultivo. Lavado broncoalveolar.

\begin{abstract}
Fiberoptic bronchoscopy is a useful procedure in the diagnosis of histoplasmosis, when the clinical material is adequately processed. Ten cases of disseminated histoplasmosis in patients with AIDS are presented here, with a mycological evaluation in culture, Mycosel ${ }^{\circledR}$ and Sabouraud's chloramphenicol agar of clinical specimens obtained through fiberoptic bronchoscopy. The yield of Mycosel ${ }^{\circledR}$ culture was $60 \%$, while in Sabouraud's chloramphenicol agar it was $20 \%$, supporting the importance of selective medium in the isolation of Histoplasma capsulatum var capsulatum from potentially contaminated clinical specimens, as well as the importance of clinical information for the laboratory as the key for a correct diagnosis.
\end{abstract}

Key-words: Histoplasmosis. AIDS. Histoplasma capsulatum var capsulatum. Isolation in culture. Bronchoalveolar lavage.

A histoplasmose é infecção causada pelo fungo termodimórfico Histoplasma capsulatum var capsulatum e o seu habitat natural é o solo enriquecido com excrementos de pássaros, morcegos e galinhas. A infecção é iniciada após inalação de microconídios sendo como regra de curso assintomático ou autolimitado, podendo resultar em variedade de manifestações clínicas: histoplasmose pulmonar aguda, histoplasmose pulmonar crônica e histoplasmose disseminada ${ }^{4}$. Todas as manifestações clínicas simulam tuberculose, sendo imprescindível o diagnóstico etiológico através de exames laboratoriais próprios ${ }^{9}$. Em pacientes com SIDA pode haver associação entre elas ${ }^{10}$ e confusão com pneumocistose pulmonar ${ }^{3}$. 0 diagnóstico clínico sem comprovação etiológica em doenças potencialmente graves leva a tratamentos empíricos que muitas vezes contribuem para morte do paciente.

0 diagnóstico de histoplasmose depende de um alto grau de suspeição clínica e devido ao diminuto tamanho $(2-4 \mu \mathrm{m}$ de diâmetro) da apresentação tecidual do fungo e à semelhança com outros elementos fúngicos leveduriformes, bem como outras estruturas não fúngicas ${ }^{12}$, 0 diagnóstico definitivo é fornecido pelo isolamento em cultivo ${ }^{9}$.

A identificação de um fungo dimórfico em qualquer material clínico tem conotação diagnóstica. Portanto, para lesões pulmonares com suspeita clínica da micose, inicialmente se avaliam espécimes obtidos por métodos não

1. Programa de Pós-graduação em Medicina da Universidade Federal do Rio Grande do Sul, Porto Alegre, RS.

Endereço para correspondência: Dr. Luiz Carlos Severo. Laboratório de Micologia/Complexo Hospitalar Santa Casa. Rua Annes Dias 285, 90020 -090 Porto Alegre, RS. Fax: 5551 214-8435.

e-mail: severo@ santacasa.tche.br

Recebido para publicação em 24/12/2003

Aceito em 4/3/2004 
invasivos: escarro; seguindo com fibrobroncoscopia ${ }^{1}$ : lavado broncoalveolar ${ }^{2}$, biópsia transbrônquica ${ }^{5}$; biópsia transcutânea ${ }^{11} \mathrm{e}$ biópsia pulmonar a céu aberto ${ }^{8}$.

0 sucesso do isolamento e a correta identificação de um fungo, bem como avaliação de sua importância clínica depende de vários fatores, como a coleta adequada do espécime clínico e 0 correto processamento do material no laboratório.

Salientar a importância do meio de cultivo para 0 diagnóstico de histoplasmose através do lavado broncoalveolar ( LBA) e lavado brônquico (LB) justifica este trabalho.

\section{MATERIAL E MÉTODOS}

Foram revisados retrospectivamente os casos de histoplasmose catalogados nos arquivos do Laboratório de Micologia do Complexo Hospitalar Santa Casa, Porto Alegre, RS. Os critérios de inclusão foram: histoplasmose disseminada em pacientes com SIDA e avaliação micológica em cultivo, de LBA ou LB.

Rotina laboratorial. Parte do líquido ( $5 \mathrm{ml})$ procedente do lavado é processado em citocentrífuga (2000rpm/15 min) e, a lâmina, com 0 esfregaço, é corada pela técnica de GomoriGrocott com metenamina argêntica (GMS) . 0 restante (10 $10 \mathrm{ml}$ ) é centrifugado ( $700 \mathrm{rpm} / 20 \mathrm{~min}$ ) com utilização do sedimento para semeadura de 3ml, respectivamente, em meios ágar-Sabouraud (DIFCO) cloranfenicol (União Química, 1\%) e $\operatorname{Mycosel}^{\circledR}$ ( BBL), processado em capela de fluxo laminar classe IIB (Trox Brasil Ltda, modelo FLV, série 636) quando havia suspeita de histoplasmose e/ou pacientes infectados pelo vírus da imunodeficiência humana (HIV), e incubados a 25으. Cultivos positivos para Histoplasma capsulatum var capsulatum foram confirmados pelo aspecto micromorfológico (macroconídios tuberculados) e caracterização do dimorfismo térmico, pela conversão para a fase leveduriforme em ágar infusão de cérebrocoração (BHI) a 37ํㅡ.

\section{RESULTADOS}

De 215 casos presentes na casuística de histoplasmose ( outubro 1978 - novembro, 2003), dez casos preencheram os critérios de inclusão. Todos os pacientes eram homens, com idade entre 29 e 57 anos, brancos e procedentes do Rio Grande do Sul. Nos achados radiológicos o padrão predominante foi infiltrado pulmonar difuso ( Figuras 1 e 2).

Em dois casos, ocorreu associação com pneumocistose (Caso 1 e 9) e em outro, com criptococose e tuberculose (Caso 8). A freqüência de isolamento do Histoplasma capsulatum var capsulatum em Mycosel ${ }^{\circledR}$ (Figura 3) foi de $60 \%$. 0 isolamento em cultivo pelo $\mathrm{SCl}$ teve a mesma positividade da microscopia (20\%). Outras técnicas diagnósticas incluíram: hemocultivo com lisecentrifugação ( Isolator ${ }^{\circledR}$ ), histopatologia , imunodifusão e cultivo de outros espécimes clínicos (Tabela 1).

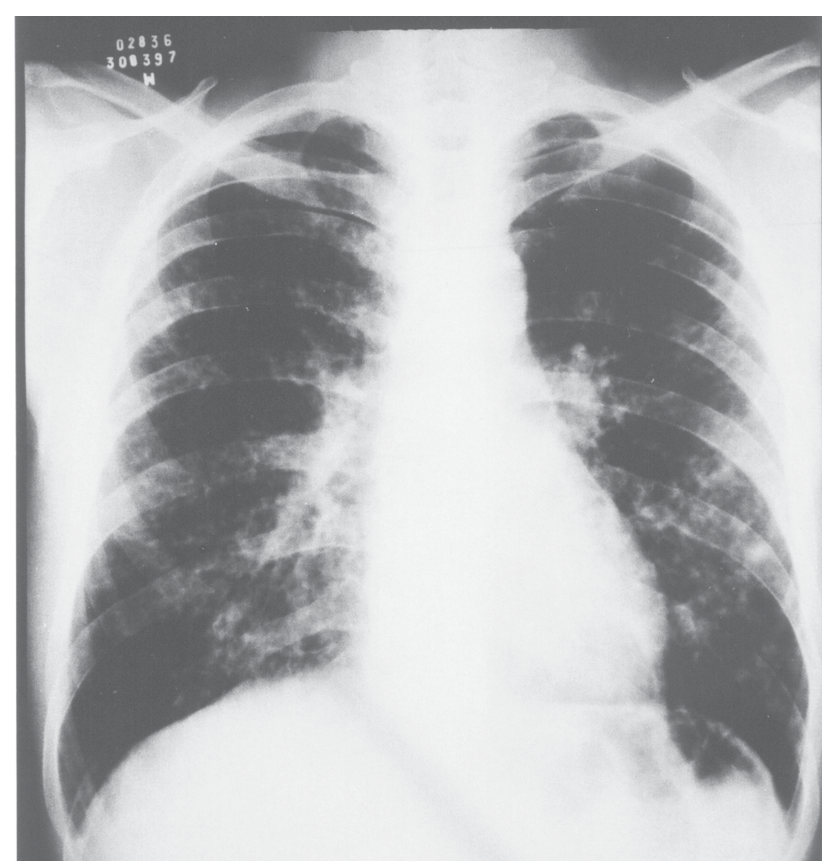

Figura 1 - Infiltração bilateral, difusa, intersticial micronodular e alveolar.

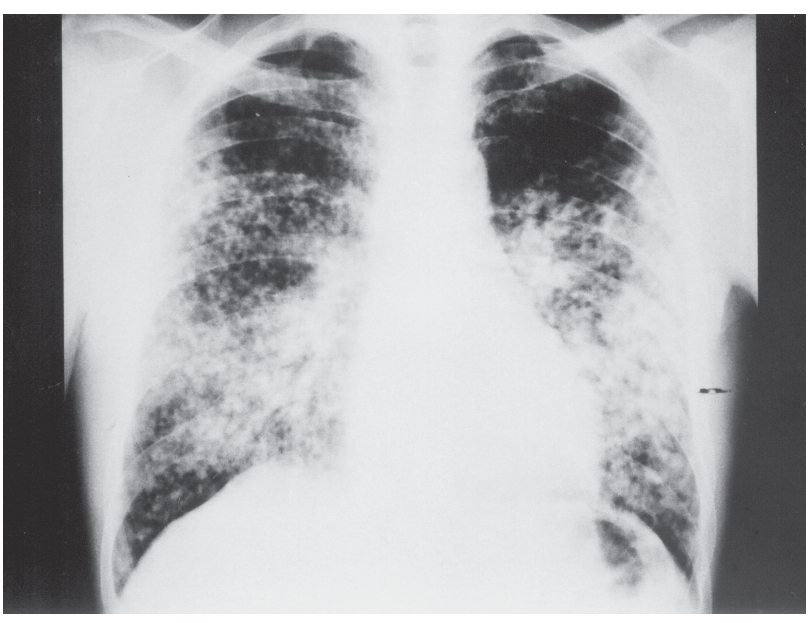

Figura 2 - Após teste terapêutico para tuberculose, progressão da infiltração com focos de consolidação de extensão broncopneumônica.

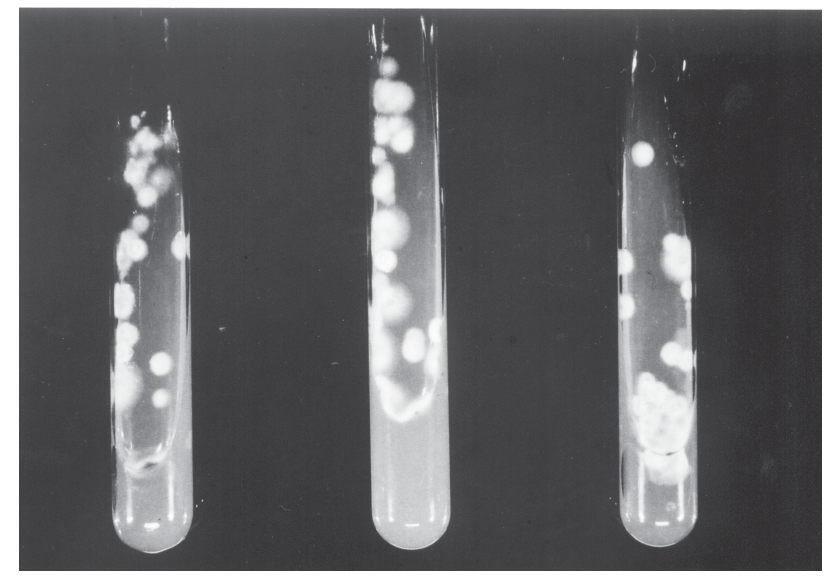

Figura 3 - Colônias isoladas a partir do lavado broncoalveolar em Mycosel $^{\circledR}$, na fase filamentosa do Histoplasma capsulatum var capsulatum cor creme, a $25^{\circ} \mathrm{C}$ 
Tabela 1 - Aspectos diagnósticos de dez casos de histoplasmose disseminada e SIDA

\begin{tabular}{|c|c|c|c|c|c|c|c|}
\hline \multirow[b]{3}{*}{ Caso } & \multirow[b]{3}{*}{ Lavado } & \multicolumn{3}{|c|}{ Espécime broncoscópico } & \multirow{2}{*}{\multicolumn{3}{|c|}{ Outras técnicas diagnósticas positivas }} \\
\hline & & \multirow{2}{*}{$\frac{\text { microscopia }}{\text { GMS }}$} & \multicolumn{2}{|c|}{ cultivo } & & & \\
\hline & & & Mycosel & $\mathrm{SCl}$ & histopatologia & IDh & cultivo \\
\hline 1 & broncoalveolar & $t^{(a)}$ & - & - & $\mathrm{NF}$ & $\mathrm{M}$ & urina \\
\hline 2 & brônquico & - & + & $\mathrm{Bac}$ & $\mathrm{NF}$ & $\mathrm{NF}$ & aspirado traqueal \\
\hline 3 & brônquico & + & + & + & pele & $\mathrm{NF}$ & $\mathrm{NF}$ \\
\hline 4 & broncoalveolar & - & + & - & pele & - & isolator $r^{\otimes}$ \\
\hline 5 & broncoalveolar & - & + & + & pulmão & - & isolator $r^{\otimes}$ \\
\hline 6 & broncoalveolar & - & - & $\mathrm{Ca}$ & $\mathrm{NF}$ & $\mathrm{NF}$ & isolator ${ }^{\circledast}$, pele \\
\hline 7 & broncoalveolar & - & + & $\mathrm{Bac}$ & pele & $\mathrm{NF}$ & isolator ${ }^{\circledast}$, pele \\
\hline $8^{(b)}$ & broncoalveolar & - & - & - & quiasma óptico & M & isolator ${ }^{\otimes}$ \\
\hline 9 & broncoalveolar & (a) & - & Af & pele & - & $\mathrm{NF}$ \\
\hline 10 & brônquico & - & + & - & $\mathrm{NF}$ & - & $\mathrm{NF}$ \\
\hline
\end{tabular}

GMS: método de Gomori-Grocott com metenamina argêntica. SCl: ágar-Sabouraud com cloranfenicol. -: negativo. +: positivo. NF: não feito. IDh: imunodifusão para histoplasmose. M: banda M. ${ }^{\left({ }^{(a)}\right.}$ : Pneumocystisjiroveci. ${ }^{(b)}$ : tuberculose pulmonar prévia e Cryptococcusneoformans var grubii isolado do líquor. Bac: bactéria. Ca: Candida albicans. Af: Aspergillus fumigatus.

\section{DISCUSSÃ0}

0 diagnóstico micológico da histoplasmose baseia-se fundamentalmente no isolamento do microrganismo de material clínico ${ }^{9}$. Neste sentido, a escolha do meio de cultivo deve levar em consideração a hipótese diagnóstica e 0 tipo de material clínico.

Lazzarini-de-Oliveira et $\mathrm{al}^{7}$, em estudo da utilidade da broncoscopia na investigação rotineira de infecções fúngicas, relatam 10 casos de histoplasmose em pacientes com SIDA, com cultivo de LBA positivo. Somente em dois casos a microscopia foi positiva. Neste estudo são especificados os meios utilizados, porém não relatam em qual houve 0 isolamento fúngico.

Salzman et $\mathrm{al}^{10}$, em um estudo de 18 casos de histoplasmose em pacientes em risco para SIDA, naqueles submetidos a fibrobroncoscopia, relatam positividade de $69 \%$ no cultivo de LBA e $14 \%$ na microscopia. No entanto, não relatam o meio de cultivo ou a coloração utilizada.

Wheat et $\mathrm{a}^{14}$, comparando métodos laboratoriais para diagnóstico de histoplasmose através de LBA, em 27 pacientes com SIDA e histoplasmose disseminada, obtiveram $70 \%$ de positividade na microscopia, utilizando duas colorações ( GMS e Giemsa) , e 89\% em cultivo. Em outro estudo da sensibilidade dos testes diagnósticos para histoplasmose, em pacientes com SIDA, Wheat ${ }^{13}$ relata positividade de $70 \%$ tanto na microscopia como no cultivo de LBA, em 72 pacientes com histoplasmose disseminada. Porém, em nenhum destes estudos foram mencionados os meios de cultivo utilizados.

Esta variabilidade encontrada em relação ao cultivo e a microscopia pode ser creditada aos diferentes métodos utilizados para detectar 0 agente etiológico, tornando difícil comparar estes dados.

0 Mycosel $^{\circledR}$ e seu similar Micobiotic ${ }^{\circledR}$ são meios seletivos indicados para isolamento de dermatófitos. A presença de antibiótico (cloranfenicol) e antifúngico (ciclo-heximida) frenam o desenvolvimento de bactérias e fungos contaminantes ${ }^{6}$, permitindo 0 isolamento do Histoplasma capsulatum var capsulatum, de crescimento mais lento.
Por fim, deve ficar claro para médicos em geral a importância de constar, no pedido de exame microbiológico de qualquer espécime obtido por broncoscopia, a hipótese de histoplasmose ou pelo menos de que o paciente tenha SIDA ou qualquer tipo de imunossupressão, para que 0 material seja semeado em meio seletivo, facilitando 0 isolamento de fungos com dimorfismo térmico.

\section{REFERÊNCIAS BIBLIOGRÁFICAS}

1. Baselski VS, Wunderink RG. Bronchoscopic diagnosis of pneumonia. Clinical Microbiology Reviews 7:533-558, 1994.

2. Baughman RP, Dohn MN, Frame PT. The continuing utility of bronchoalveolar lavage to diagnose opportunistic infection in AIDS patients. American Journal of Medicine 97:515-522, 1994.

3. Baughman RP, Strohofer SS, Clinton BA, Nickol AD, Frame PT. The use of an indirect fluorescent antibody test for detecting Pneumocystis carinii. Archives of Pathology Laboratory Medicine 113:1062-1065, 1989.

4. Goodwin RA, Des Prez RM. Histoplasmosis. State of the art. American Review of Respiratory Disease 117:929-956, 1978.

5. Huang CT, McGarry T, Cooper S, Saunders R, Andavolu R. Disseminated histoplasmosis in the acquired immunodeficiency syndrome. Report of five cases from a nonendemic area. Archives of Internal Medicine 147:1181-1184, 1987.

6. Koneman EW, Roberts GD. Williams \& Wilkins (eds) Practical laboratory mycology, $3^{\text {rd }}$ edition, Baltimore, 1985.

7. Lazzarini-de-Oliveira LC, Arantes AA, Caiuby MJM. Utilidade da investigação rotineira de infecção fúngica pela broncoscopia em pacientes infectados ou não pelo HIV em um hospital geral, referência para SIDA. Revista da Sociedade Brasileira de Medicina Tropical 32:255-261, 1999.

8. Prechter CG, Prakask UBS. Bronchoscopy in the diagnosis of pulmonary histoplasmosis. Chest 95:1033-1036, 1989.

9. Rippon JW. Histoplasmosis (Histoplasmosis capsulati). In: Medical Mycology, WB Saunders Company (eds) $3^{\text {rd }}$ edition, Philadelphia, p. 381 423, 1988

10. Salzman SH, Smith RL, Aranda CP. Histoplasmosis in patients at risk for the acquired immunodeficiency syndrome in a nonendemic setting. Chest 93: 916-921, 1988.

11. Severo LC, Rizzon CFC, Roesch EW, Oliveira FM, Porto NS. Chronic pulmonary histoplasmosis in Brazil: Report of two cases with cavitation diagnosed by transthoracic needle biopsy. Revista do Instituto de Medicina Tropical de São Paulo 39:293-297, 1997. 
12. Tewari R, Wheat LJ, Ajello L. Agents of histoplasmosis. In: Topley \& Wilson's (eds) Medical mycology. Microbiology and microbial infections, $9^{\text {th }}$ edition, London, p. 373-393, 1998.

13. Wheat LJ. Histoplasmosis in AIDS. AIDS Clinical Care 4:1-4, 1992.

14. Wheat LJ, Connolly-Stringfield P, Williams B, Connolly K, Blair R, Bartlett M, Durkin M. Diagnosis of histoplasmosis in patients with the acquired immunodeficiency syndrome by detection of Histoplasma capsulatum polysaccharide antigen in bronchoalveolar lavage fluid. American Review Respiratory Diseases 145:1421-1424, 1992. 